\title{
"O PREÇO DO PRECONCEITO NOS 'COUROS””: (DES)CONSTRUÇÕES ACERCA DA EDUCAÇÃO SEXUAL NA ESCOLA
}

\author{
Elaine de Jesus Souza \\ Universidade Federal do Cariri \\ elaine.js.sd@hotmail.com \\ Elânia Fracisca da Silva \\ Universidade Federal do Cariri \\ elania964@gmail.com
}

José Felipe Alves Sousa

Universidade Federal do Cariri felipesousaalves01@gmail.com

Eugerbia Paula da Rocha

Universidade Federal do Cariri

eugerbiarochabs@gmail.com

\begin{abstract}
Resumo
A Educação Sexual constitui um processo contínuo e planejado que abrange distintas abordagens e metodologias acerca de sexualidade, corpo e gênero. Este trabalho engloba relatos de um projeto de extensão desenvolvido com cerca de 206 estudantes do Ensino Fundamental e Ensino Médio em três escolas da rede pública (uma municipal e duas estaduais) do Ceará, que teve como principal objetivo incorporar a Educação Sexual numa perspectiva sociocultural, nos currículos escolares e acadêmicos, por meio de ações pedagógicas que ultrapassam as abordagens biológico-higienistas. As estratégias didático-metodológicas utilizadas nos 15 encontros foram grupos focais organizados em minicursos, oficinas de zines, problematização de artefatos culturais, jogos e rodas de conversas acerca das temáticas da Educação Sexual. Os/as estudantes tiveram a oportunidade de expor opiniões, dúvidas e sugerir temas para serem debatidos. Assim, evidenciamos a necessidade de discutir, de modo contínuo e sistemático, essas temáticas na escola, instigando os/as alunos/as a desconstruírem preconceitos e discriminações acerca das identidades e diferenças sexuais e de gênero.
\end{abstract}

Palavras-chave: Educação Sexual. Sexualidade. Gênero. Artefatos culturais.

\section{“THE PRICE OF PREJUDICE IN 'LEATHER"” (DES) CONSTRUCTIONS ABOUT SEXUAL EDUCATION AT SCHOOL}

\begin{abstract}
Sex Education is a continuous and planned process that encompasses different approaches and methodologies about sexuality, body and gender. This work includes reports of an extension project developed with about 206 elementary and high school students in three public schools (one municipal and two state) in Ceará, whose main objective was to incorporate Sex Education in a sociocultural perspective, in school and academic curricula, through pedagogical actions that go beyond biologicalhygienist approaches. The didactic-methodological strategies used in the 15 meetings were focus groups organized in mini-courses, workshops for zines, problematization of cultural artifacts, games and rounds of conversations about the themes of Sexual Education. The students had the opportunity to express their opinions, doubts and suggest topics to be discussed. Thus, we highlight the need to discuss these themes at school in a continuous and systematic way, instigating students to deconstruct prejudices and discrimination about sexual and gender identities and differences.
\end{abstract}

Key Words: Sexual Education. Sexuality. Gender. Cultural artifacts. 


\title{
"EL PRECIO DEL PREJUICIO EM 'CUEROS"”: (DES) CONSTRUCCIONES SOBRE LA EDUCACIÓN SEXUAL EN LA ESCUELA
}

\begin{abstract}
Resumen
La educación sexual es un proceso continuo y planificado que abarca diferentes enfoques y metodologías sobre sexualidad, cuerpo y género. Este trabajo incluye informes de un proyecto de extensión desarrollado con unos 206 estudiantes de educación primaria y secundaria en tres escuelas públicas (una municipal y dos estatales) en Ceará, cuyo objetivo principal era incorporar la educación sexual en una perspectiva sociocultural, en los planes de estudio escolares y académicos, a través de acciones pedagógicas que van más allá de los enfoques biológicos-higienistas. Las estrategias didáctico-metodológicas utilizadas en las 15 reuniones fueron grupos focales organizados en minicursos, talleres para revistas, problematización de artefactos culturales, juegos y rondas de conversaciones sobre los temas de Educación Sexual. Los estudiantes tuvieron la oportunidad de expresar sus opiniones, dudas y sugerir temas para discutir. Por lo tanto, destacamos la necesidad de discutir estos temas en la escuela de manera continua y sistemática, instigando a los estudiantes a deconstruir prejuicios y discriminación sobre identidades y diferencias sexuales y de género.
\end{abstract}

Palabras Clave: Educación sexual. Sexualidad Género Artefactos culturales. 


\section{INTRODUÇÃO}

A Educação Sexual constitui um processo contínuo e planejado que abrange distintas abordagens e metodologias acerca de sexualidade, corpo e gênero, visando desconstruir preconceitos e discriminações que compõem a homofobia. A partir de uma perspectiva sociocultural, tal campo transdisciplinar possibilita o reconhecimento das diferenças e questionamento dos discursos que a produzem, oportunizando múltiplos aprendizados acerca da diversidade sexual e demais identidades.

A escola compreende um espaço de desenvolvimento social e pessoal, exercendo um papel que vai além da simples difusão de conteúdos didáticos, pois assume um compromisso ético, social e político, assim faz-se indispensável a discussão de temas como, diversidade sexual e desigualdades de gênero. Contudo, diante do contexto sociocultural religiosofundamentalista do estado Ceará, a inclusão da Educação Sexual nos currículos escolares encontra resistências e enfrenta diversos desafios, tais como carência na formação docente inicial e continuada, preconceitos como o machismo, sexismo e a homofobia.

Nesse cenário regional, o Grupo Gay da Bahia ${ }^{1}$ destaca que "[...] o Ceará é o quarto estado que mais mata gays, travestis, transexuais", a manchete explicita que, em 2017, 30 pessoas da comunidade LGBT - lésbicas, gays, bissexuais, travestis e transexuais - foram assassinadas em crimes ocasionados em decorrência da homofobia. Segundo a Associação Nacional de Travestis e Transexuais (ANTRA), o Ceará é o segundo estado do País em assassinato de pessoas Trans, apontando 11 vítimas de homicídios em 2019 (BENEVIDES; NOGUEIRA, 2020).

Em contrapartida, a incorporação da Educação Sexual nos currículos escolares e acadêmicos incitaria a desconstrução de preconceitos e discriminações ao articular as dimensões socioculturais de sexualidade, corpo e gênero, valorizando o diálogo entre distintos grupos sociais e campos do saber, por meio de questionamentos e problematizações acerca das relações e assimetrias de gênero, machismo, homofobia, transexualidade, travestilidade, padrões de beleza e heteronormatividade. Por meio de metodologias dinâmicas e plurais que ultrapassem as abordagens biológico-higienistas, promovam o engajamento dos/as docentes e discentes na luta diária contra toda forma de preconceito e exclusão das diferenças.

Conforme Louro (1997), a escola desempenha um papel importante na (des)construção de preconceitos, diferenças e identidades sexuais e de gênero, pois, como parte de uma sociedade que discrimina, usualmente, produz e reproduz desigualdades sexuais,

\footnotetext{
${ }^{1}$ Disponível em: https://g1.globo.com/ce/ceara/noticia/ceara-e-o-quarto-estado-que-mais-mata-gays-travestis-etransexuais.ghtml. Acesso 17 jan. 2020.
} 
de gênero, raça, etnia, sobretudo, ao constituir-se como um espaço sexualizado e generificado marcado por relações de poder-saber. Desse modo, a criação de parcerias entre escola e universidade é necessária para que discentes e docentes se aliem na disseminação de (in)formações acerca da Educação Sexual.

Nesse rumo, o projeto de extensão teve como principal objetivo incorporar a Educação Sexual numa perspectiva sociocultural, nos currículos escolar e acadêmico, por meio de ações pedagógicas que ultrapassam as abordagens biológico-higienistas, dando destaque a sexualidade, identidades, gênero e corpo. A partir da problematização de artefatos e pedagogias culturais, buscamos estimular uma análise crítica acerca do modo como discursos são (re)produzidos, instituindo saberes e práticas acerca de sexualidade e gênero na escola.

\section{UMA (IN)CONTÁVEL HISTÓRIA ACERCA DA EDUCAÇÃO SEXUAL?}

(Des)continuidades e rupturas narram uma história da Educação Sexual fragmentada e instável marcada por distintos discursos e mecanismos de poder-saber. Trata-se de uma história em constante construção, em que essencialismos biológicos e normatizações (res)surgem, em diferentes épocas e contextos, sendo passíveis de problematizações. Os discursos produzidos historicamente em diversas instâncias sociais costumam reforçar uma Educação Sexual alicerçada em saberes biológicos, médicos e dogmas religiosos. Tais discursos científicos marcam abordagens em currículos escolares e acadêmicos que, usualmente, desconsideram as dimensões culturais, sociais e políticas de sexualidade, corpo e gênero, temáticas centrais nesse campo transdisciplinar (SOUZA, 2018).

O filósofo francês Michel Foucault, na sua obra "História da sexualidade I: a vontade de saber" narra como a sexualidade foi discutida no decorrer dos séculos. Foucault (2015) argumenta que, desde o século XVIII, houve uma incitação aos discursos acerca de sexo e sexualidade; em oposição à hipótese repressiva, uma pluralidade de discursos proliferou, permitindo a (re)produção de mecanismos de poder.

Em resumo, a hipótese repressiva se refere a ideia de que, historicamente, os discursos sobre sexo e sexualidade tenham sofrido repressão e/ou interdição, em contraponto Foucault defende uma "proliferação discursiva". Ao invés da censura e interdição, no século XVIII desenvolveu-se uma incitação dos discursos sobre sexo: "tudo deve ser dito", constituindo um mecanismo de poder disseminado em instâncias sociais, como a Igreja Católica; visto que a multiplicação dos discursos constituía uma forma de controle e regulação do sexo e da sexualidade de acordo com um padrão social, legitimado historicamente (FOUCAULT, 2015). Essa proliferação de discursos acerca da sexualidade continua sendo incitada no século XXI, principalmente por meio de artefatos e pedagogias culturais veiculadas na mídia, como 
filmes, novelas, músicas, revistas, programas de TV, além de saberes e práticas das ciências até a religião continua utilizando seus dogmas para impor um modo legítimo de sexualidade.

Historicamente, a Educação Sexual foi utilizada como um "dispositivo de sexualidade", visto que abordagens prescritivas e essencialistas, como a biológico-higienista, constituíam mecanismos de poder, ao exercer uma função estratégica e regulatória no controle das Infecções Sexualmente Transmissíveis (IST) e da gravidez na juventude. Ao relacionar sexualidade e reprodução, contribuíam para a naturalização da heterossexualidade e a marginalização de outras identidades sexuais e de gênero. Embora a Educação Sexual biológico-higienista não priorize o conceito de gênero, ao instituir um conjunto de essencialismos e normatizações pressupõe diferenças sexuais e reforça oposições binárias, como masculino/feminino, natureza/cultura, heterossexual/homossexual.

No início dos anos 1980, o surgimento da Aids instituiu novos discursos (bio)médicos acerca da sexualidade. Ao ser denominada de "o mistério homossexual", "câncer e/ou peste gay", a emergência da síndrome reforçou preconceitos e discriminações que compõem a homofobia. A forma de transmissão da Aids suscitou discussões em distintos âmbitos sociais, principalmente nos currículos escolares, disseminando as abordagens biológico-higienistas da Educação Sexual. De outro modo, a luta contra a Aids ocasionou um deslocamento nos discursos sobre sexualidade, mudando o foco das identidades para práticas sexuais, com ênfase na prevenção e prática do sexo seguro. Além disso, houve uma diversificação de movimentos sexuais e de gênero, ampliando as informações sobre a homossexualidade e o questionamento de binarismos e relações de poder (FURLANI, 2008; LOURO, 2001; SOUZA, 2018).

$\mathrm{Na}$ conjuntura social e política contemporânea, as questões contempladas pela Educação Sexual estão cada vez mais em discussão, Leis (2003, p.341) já ressaltava que “[...] nos encontramos na época mais sexualizada de toda a História” e, acrescentamos, generificada. Butler (2000, p.04) destaca que:

\footnotetext{
Desde os anos sessenta, o debate sobre as identidades e as práticas sexuais e de gênero vem se tornando cada vez mais acalorado, especialmente provocado pelo movimento feminista, pelos movimentos de gays e de lésbicas e sustentado, também, por todos aqueles e aquelas que se sentem ameaçados por essas manifestações.
}

Nessa perspectiva, esses movimentos sociais permitiram a criação de novas formas de estilo de vida, desafiando essa sociedade heteronormativa, posto que, começaram a lutar por igualdade de gênero tanto no poder político, educacional, econômico, mercado de trabalho e outras instâncias. Foram grandes os avanços comparados há 60 anos, mas muito ainda precisa ser debatido, principalmente em relação a temática de gênero. 
Homens e mulheres certamente não são construídos apenas através de mecanismos de repressão ou censura, eles e elas se fazem, também, através de práticas e relações que instituem gestos, modos de ser e de estar no mundo, formas de falar e de agir, condutas e posturas apropriadas (e, usualmente, diversas). Os gêneros se produzem, portanto, nas e pelas relações de poder (LOURO, 1997, p.41, grifos da autora).

As relações de poder regem a sociedade, ditando o que é ou não apropriado, como os indivíduos e grupos devem se comportar, agir, falar, tornando "anormal" os que ousar fugir desse padrão social. No entanto, no decorrer do último século, vivenciamos uma desconstrução histórica e sociocultural, isto é, os discursos e as relações de poder estão sendo questionados e problematizados, principalmente a partir de artefatos e pedagogias culturais que instigam novos olhares e novas linguagens acerca das questões de corpo, sexualidade e gênero.

Durante a formação docente pouco se fala de corpo, mais precisamente em Anatomia Humana que dá ênfase ao corpo humano como protagonista do conhecimento a ser desenvolvido, porém com uma visão biológico-higienista e consequentemente não enxergando-o como uma construção sociocultural. Segundo Silva (2014), o corpo que aparece nos textos e aulas é fragmentado e biomedicalizado. Louro (2000) aponta uma correlação na construção histórica do disciplinamento dos corpos e das mentes, tornando os processos de escolarização preocupados em vigiar, controlar, modelar, corrigir e construir os corpos de meninos e meninas, de jovens homens e mulheres.

De modo contraditório, o dispositivo de sexualidade (FOUCAULT, 2015), ao ser construído com uma função estratégica de controle do sexo e do corpo individual e social, possibilitou a proliferação de discursos que evidenciam a existência de algo além de corpos, órgãos, funções reprodutivas, sistemas anatômicos e fisiológicos, que as ciências biológicas pautadas no saber (bio)médico disseminaram como conhecimentos universais e legítimos.

De outro modo, uma ruptura na linguagem escolar possibilita compreender que a sexualidade consiste em um dispositivo histórico que rege o controle de corpos, prazeres, discursos, sujeitos e relações de poder produzidos na e pela cultura. Destarte, “[...] a sexualidade está na escola porque ela faz parte dos sujeitos, ela não é algo que possa ser desligado ou algo do qual alguém possa se despir” (LOURO, 1997, p. 81). A sexualidade está presente no indivíduo, que a vivencia como uma constante construção. Entretanto, no âmbito escolar, a heteronormatividade se (re)produz numa tentativa incessante de moldar a sexualidade para ser reconhecida e legitimada somente a heterossexualidade, logo afastar-se dela é considerado um desvio, que tende a ser vigiado e corrigido (LOURO, 2009).

Nessa perspectiva, a diversidade sexual compreende diferentes expressões e vivências de sexualidade e de gênero, englobando as identidades sexuais - homossexuais, 
heterossexuais, bissexuais, assexuais - e de gênero - travestis, transexuais (LOURO, 1997; SOUZA; SILVA; SANTOS, 2016). Ademais, cabe destacar que o termo homofobia engloba um conjunto de violências físicas e psicológicas, preconceitos e discriminações perpetrados contra indivíduos e grupos LGBT e outras formas de diversidade sexual, devido a comportamentos e vivências divergentes dos padrões heteronormativos (JUNQUEIRA, 2009).

Em contrapartida, ao problematizar saberes e práticas sobre sexualidade, a teoria cultural permite reconhecer a construção de uma política identitária articulada ao conceito de gênero, visto que, este, engloba as múltiplas possibilidades de expressar masculinidades e feminilidades, ampliando os modos de vivenciar as sexualidades, indo além das formas hegemônicas. A teoria cultural examina os sentidos produzidos em torno de sexualidade e seus efeitos nas vivências e expressões humanas, tendo como principal tarefa a desconstrução de teorias essencialistas que concebem a sexualidade como algo dado e fixo no sujeito. Esse processo de análise consiste em apontar o caráter construído dos acontecimentos, a partir da historicização e desnaturalização de saberes e normas, o que tem sido fundamental para o reconhecimento de múltiplas identidades sexuais e de gênero, entre outras, produzidas no interior da cultura e nas instituições sociais, como a escola (LOURO, 1997; MEYER, 2004; SOARES, 2008).

Além da sociedade agir de forma conservadora, a religião predomina nas políticas públicas e nos corredores escolares, tornando-se um dos fatores que limita esse campo transdisciplinar a uma abordagem biológico-higienista, disseminando preconceitos e essencialismos acerca de sexualidade, corpo, gênero, identidades/diferenças. Ao se falar em Educação Sexual, a maioria das pessoas a restringe à prevenção contra Infecções Sexualmente Transmissíveis (IST), gravidez na adolescência e ao ato sexual, devido à falta de (in)formação e/ou princípios fundamentalistas (FURLANI, 2008).

Em novembro de 2015, o tema transversal "Orientação Sexual” foi retirado da Base Nacional Comum Curricular (BNCC), antes contemplado pelos Parâmetros Curriculares Nacionais (PCN), e não foi inserido entre os temas integradores do novo documento. Especialistas em políticas públicas sobre gênero e sexualidade ressaltaram que a omissão da Educação Sexual representa um retrocesso, visto que essas temáticas somente aparecem de modo pontual na BNCC, ainda assim em uma abordagem limitada à anatomia e fisiologia do corpo humano na disciplina Biologia, desconsiderando dimensões identitárias, socioculturais e políticas. Essa omissão da Educação Sexual articula-se com o mesmo princípio religiosofundamentalista que, em 2014, excluiu as questões de gênero e sexualidade do Plano Nacional da Educação e de alguns planos estaduais e municipais (SOUZA, 2018). 
Em contrapartida, a Organização das Nações Unidas para a Educação, a Ciência e a Cultura (Unesco) $)^{2}$, em junho de 2016, se posicionou a favor da inclusão da Educação Sexual nas escolas, enfatizando que as discussões sobre sexualidade e gênero contribuem para uma educação baseada na equidade de direitos entre as distintas identidades sexuais e de gênero.

Souza, Silva e Santos (2016) salientam o quanto a diversidade de corpos, sexualidades e gêneros torna-se visível na escola, mesmo com os muros e amarras que tentam enquadrar todos/as em um padrão heteronormativo, as diferenças se sobressaem, o que evidencia a necessidade de questionamento acerca de seus modos de produção e/ou silenciamento.

Sendo a escola um espaço de diversidade, toda tentativa de ocultamento impacta a formação pessoal e social dos/as estudantes. Contudo, para famílias conservadoras e religiosas-fundamentalistas, a Educação Sexual ainda é vista como exposição ao sexo precoce, tornando-se um desafio para docentes abordar tais temáticas em sala de aula, pois encontram resistências e enfrentamentos. Nesse rumo, demanda-se uma emergente reflexão e intervenção de uma equipe multidisciplinar que promova ações didático-pedagógicas para incorporação da Educação Sexual, abrangendo toda comunidade escolar, famílias, gestão, discentes, docentes, para construir um espaço aberto de diálogo e acolhimento das diferenças.

\section{METODOLOGIAS ALTERNATIVAS PARA UMA ABORDAGEM SOCIOCULTURAL DA EDUCAÇÃO SEXUAL}

O presente trabalho resulta de um projeto de extensão desenvolvido no município de Brejo Santo-CE, onde foram realizados 15 encontros de grupos focais em três escolas: duas de Ensino Médio e uma de Ensino Fundamental/Anos Finais, com a participação de 206 estudantes. Cabe informar que utilizamos nomes fictícios para não identificar os/as participantes. Durante três meses, as ações do projeto foram desenvolvidas semanalmente nas escolas. As estratégias didático-metodológicas utilizadas nos encontros foram minicursos, oficinas de zines, problematização de artefatos culturais, jogos e rodas de conversas acerca das temáticas da Educação Sexual.

Essas metodologias alternativas evidenciam uma série de possibilidades para abordagem sociocultural da Educação Sexual, sobretudo ao problematizar a linguagem, estimulando o constante (auto)questionamento e alertamos os/as jovens acerca de conteúdos sexistas, misóginas, machistas e homofóbicos que (re)produzimos por estarem tão presentes no nosso cotidiano, que, por vezes, nem contamos o viés preconceituoso. Reside aí a relevância de incorporar essa temática na formação dos/as educadores/as apresentando

\footnotetext{
${ }^{2}$ Disponível em: <https://nacoesunidas.org/unesco-defende-educacao-sexual-e-de-genero-nas-escolas-paraprevenir-violencia-contra-mulheres/>. Acesso em: 27 ago. 2016.

Cidadania em Ação: Revista de Extensão e Cultura, Florianópolis (SC), v. 4, n. 1, jan./jun. 2020.
} 
estratégias didático-metodológicas potentes para que possam (re)criar na sua área de atuação e inserir nos currículos escolares.

Nesse sentido, existem diversas metodologias didáticas potentes para incluir a Educação Sexual na escola, por exemplo, os grupos focais, que, além de contribuir com a pesquisa, foram realizados com professores/as e alunos/as, por meio de minicursos e oficinas referentes a um tema específico. A fim de possibilitar engajamento entre os/as participantes se faz necessário a escolha de um ambiente familiar para os encontros, podendo ser a escola um espaço que todos/as conheçam e/ou compartilhem. Os grupos focais constituem uma técnica eficaz para a produção de informações, ao promover interações grupais entre os/as participantes com o objetivo de provocar discussões, atitudes, opiniões, respostas, reações acerca de determinada temática a partir de textos, filmes, questões, entre outras dinâmicas que favoreçam a interatividade e a (re)construção de conhecimentos (DORNELLES, 2013; GOMES, 2005).

Essa metodologia proporcionou ao grupo de discentes participantes do projeto: compartilhamento de saberes, expressão de opiniões, dúvidas e informações sobre as temáticas sexualidade, corpo e gênero, proporcionando aprender e disseminar as informações adquiridas em um linguajar popular para os demais membros da sociedade.

Os relatos obtidos por meio dos grupos focais corroboram, ainda, a necessidade de
auxílio e a insuficiência de suporte oferecida aos adolescentes, já que muitos deles,
em diferentes grupos, relataram a dificuldade que possuíam de conversar com seus
pais sobre determinados assuntos (como sexualidade, uma vez que era considerado
um tabu debater este tema), [...] (como qual o melhor momento para o início da vida
sexual) eram ignorados. (FREITAS et al, 2016, p. 554).

Na busca por suportes à juventude, faz-se necessário uma inovação na abordagem da Educação Sexual, para que seja incorporada nos currículos escolar e acadêmico em uma perspectiva sociocultural. Nessa direção, recriamos uma outra metodologia utilizada no projeto para contextualizar a temática, por meio da problematização de artefatos culturais, ou seja, problematizar significa realizar um movimento de análise crítica, observando como foram construídas diferentes soluções para um problema (FOUCAULT, 2017). Artefatos culturais constituem as pedagogias culturais, pois, mesmo sem o objetivo explícito de educar/ensinar, representam instrumentos potentes para veicular uma variedade de saberes e práticas influentes na produção de identidades e diferenças (SILVA, 2015). Como instrumentos resultantes de uma construção social, englobam além dos artefatos pedagógicos como livros, apostilhas, cartilhas, também veículos midiáticos - revistas, filmes, músicas, novelas, jornais, propagandas, sendo (re)produzidos por meio da problematização de discursos que problematizam relações de poder que instituem os/as sujeitos/as e a cultura (MAGALHÃES, RIBEIRO; 2013; SILVA, 2015). 
Nesse contexto, as temáticas da Educação Sexual foram trabalhadas com base em (in)formações e metodologias dinâmicas, visando o engajamento e a atenção dos/as jovens, assim a coordenadora do projeto em parceria com os/as bolsistas buscaram conduzir o projeto de forma didática e produtiva. Desse modo, a partir das metodologias desenvolvidas, observamos as representações dos/as alunos/as sobre temas, como diversidade sexual, sexualidade, corpo, gênero, machismo e homofobia marcantes no contexto sociocultural vigente.

\section{PROBLEMATIZAÇÃO DE ARTEFATOS CULTURAIS}

No primeiro encontro, realizamos a apresentação do projeto de extensão sobre os conceitos que envolvem a Educação Sexual, como sua própria definição, identidade de gênero, orientação sexual, sexo, sexualidade, corpo, homofobia. E no decorrer dos encontros discutimos temáticas, tais como gravidez entre jovens, machismo, bem como os/as alunos/as participantes foram sugerindo outros temas, como: câncer de mama e de próstata (outubro rosa e novembro azul), sistema sexual feminino e masculino (abordagem biológicahigienista), métodos contraceptivos e IST (saúde sexual e prevenção). Durante o primeiro encontro, com os/as alunos/as e com os/as professores/as, observamos o quanto as pessoas que partilharam desse momento não possuem familiaridade com a temática, portanto, buscamos proporcionar um ambiente onde se sintam confortáveis para expor suas opiniões, dúvidas e indagações.

No primeiro encontro dos grupos focais com os/as professores/as, a participante Diana advertiu: "eu não vejo em que posso usar a Educação Sexual na Física, isso é coisa para a biologia, não é para minha disciplina”. Tal fala além de evidenciar a carência dessas temáticas nas Licenciaturas, sobretudo nos cursos de Física, Química e Matemática, corrobora com a ideia equivocada de que somente os/as professores/as de Ciências/Biologia teriam a responsabilidade de abordar essas questões.

Em contraponto, no primeiro encontro com os/as discentes, estes/as relataram as dificuldades em discutir as temáticas da Educação Sexual com a família. Algumas alunas ressaltaram que em suas casas não existe conversa sobre sexo, talvez por receio de que tal diálogo incentivaria uma iniciação sexual; um aluno relatou que teve o apoio da irmã para procurar um urologista e isso o ajudou bastante, na sequência a aluna Angélica relatou: "tenho duas amigas da minha idade que estão grávidas, minha mãe me chamou para conversar e me pediu que no momento que eu me sentisse pronta, ela me levaria a um ginecologista, era só pedir, me senti segura pois, ela tem medo que eu faça igual a minhas amigas".

Cidadania em Ação: Revista de Extensão e Cultura, Florianópolis (SC), v. 4, n. 1, jan./jun. 2020. 
Para Furlani (2011), a abordagem biológico-higienista ainda predomina nos espaços educativos e discursos pedagógicos, visto que se restringe à dimensão biológica presente nas aulas de Ciências e de Biologia. Embora seja imprescindível a discussão de temas como saúde sexual e prevenção contra IST e gravidez entre jovens, cabe analisar criticamente um currículo biologicista e limitado, que não reconhece as dimensões socioculturais e políticas de sexualidade e gênero (FURLANI, 2011).

Ao entender a Educação Sexual como um campo transdisciplinar constituído por discursos sobre sexualidade, corpo e gênero, parece produtivo promover mais que uma conexão entre diferentes disciplinas e/ou campos de saber. Essa noção de transdisciplinaridade engloba um modo de pensar que atravessa todas as disciplinas, porém não se restringe a elas, pois a Educação Sexual pressupõe a (des)construção de saberes e práticas nos currículos escolares com diferentes perspectivas (SOUZA, 2018).

A maioria dos encontros do projeto envolveu a problematização de artefatos culturais, por meio da exibição de vídeos e músicas conforme tabela 1, ao final de cada vídeo e/ou música ocorreram as discussões, deixando cada aluno/a à vontade para expor sua opinião:

Tabela1: Discussão dos vídeos exibidos aos/as estudantes.

\begin{tabular}{|c|c|c|}
\hline Vídeos & Aluno/a & Comentários \\
\hline $\begin{array}{l}\text { Pablo Vittar “indestrutível" } \\
\text { https://www.youtube.com/watch?v=O8B72HzTuww } \\
(23 / 09 / 2019)\end{array}$ & Juliana & $\begin{array}{l}\text { "Eu presencio cenas } \\
\text { homofóbicas todos os dias na } \\
\text { escola, seja na aula, no intervalo } \\
\text { ou na saída, se tornou algo } \\
\text { comum aqui!" }\end{array}$ \\
\hline $\begin{array}{l}\text { Shame no more } \\
\text { https://www.youtube.com/watch?v=aqaLwzWVi8Q } \\
(23 / 09 / 2019)\end{array}$ & Júlio & $\begin{array}{l}\text { "Seria bom que pelo menos por } \\
\text { um dia, os homofóbicos fossem } \\
\text { homossexuais, só assim } \\
\text { saberiam o preço do preconceito } \\
\text { nos 'couros".". }\end{array}$ \\
\hline$(23 / 09 / 2019)$ & Marcelo & $\begin{array}{l}\text { "Ave, então no mundo só teria } \\
\text { viado? Pois eu preferia ser a } \\
\text { resistência hetero!" }\end{array}$ \\
\hline $\begin{array}{l}\text { Cenas da novela “A força do Querer" (Rede Globo), da/o } \\
\text { personagem Ivana/Ivan com a música "True colors" de } \\
\text { Cyndi Lauper. } \\
\text { https://www.youtube.com/watch?v=tuoerRjM2fA } \\
(23 / 09 / 2019)\end{array}$ & Pedro & $\begin{array}{l}\text { "Será que é realmente } \\
\text { necessário, uma pessoa passar } \\
\text { por todo esse sofrimento para ser } \\
\text { aceita? Poxa o corpo é dela, é } \\
\text { uma decisão dela, não é minha, } \\
\text { não é sua, o que cabe a mim e a } \\
\text { todos/as nós é respeitar". }\end{array}$ \\
\hline $\begin{array}{l}\text { O seriado Chaves e uma discussão feminista } \\
\text { https://www.youtube.com/watch?v=rvFjW0Qk-NY } \\
(26 / 09 / 2019)\end{array}$ & Berenice & $\begin{array}{l}\text { "Nosso trabalho e importância na } \\
\text { sociedade tem que ser } \\
\text { reconhecida e valorizada, não } \\
\text { somos objetos para pertencer a } \\
\text { alguém." }\end{array}$ \\
\hline $\begin{array}{l}\text { Debate entre a sexóloga Laura Muller e um integrante do } \\
\text { grupo Raça Negra no Programa Altas Horas (Rede } \\
\text { Globo). } \\
\text { https://www.youtube.com/watch?v=2OFC8K2kq1I } \\
(23 / 09 / 2019)\end{array}$ & Mário & $\begin{array}{l}\text { "Eu concordo com o "cara", } \\
\text { criança não tem que saber o que } \\
\text { é corpo, se não vão crescer tudo } \\
\text { "pervertidas"." }\end{array}$ \\
\hline $\begin{array}{l}\text { Culto ao corpo e a sexualidade infantil. } \\
\text { https://www.youtube.com/watch?v=ld2mcr9vQUQ }\end{array}$ & Angélica & 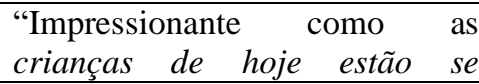 \\
\hline
\end{tabular}

Cidadania em Ação: Revista de Extensão e Cultura, Florianópolis (SC), v. 4, n. 1, jan./jun. 2020. 


\begin{tabular}{|l|l|l|}
\hline (23/09/2019) & & $\begin{array}{l}\text { tornando adultas mais cedo e } \\
\text { começando a namorar cedo } \\
\text { também, sem informação correta } \\
\text { por isso estão sendo pais e máes } \\
\text { cedo e pegando IST também." }\end{array}$ \\
\hline $\begin{array}{l}\text { Bráulio Bessa: poema sobre gêneros } \\
\text { https://www.youtube.com/watch?v=gb1hbX2s9Ho\&t=73s } \\
(11 / 10 / 2019)\end{array}$ & Flávia & $\begin{array}{l}\text { "Por que as pessoas não aceitam } \\
\text { as escolhas dos outros? Seria } \\
\text { bom se espalhassem esse poema } \\
\text { pelos corredores da escola." }\end{array}$ \\
\hline
\end{tabular}

Fonte: Dados da pesquisa (2019).

Tais comentários dos/as discentes abrigam contradições, reflexões e (des)construções suscitadas a partir da exibição de vídeos acerca das temáticas da Educação Sexual, tais como diversidade sexual, heteronormatividade, homofobia, transexualidade, feminismo, corpo e sexualidade infanto-juvenil, gênero, entre outras questões abordadas durante os encontros do projeto.

A fala da aluna Juliana contradiz a professora Soraia, que ao ser questionada se existe homofobia na escola, afirmou: "não existe, o que vemos são brincadeirinhas entre os/as alunos/as", vale salientar que tanto Juliana como Soraia pertencem a mesma escola. Tais contradições evidenciam a frequente banalização de práticas homofóbicas "sutis", ou seja, expressas na forma de "brincadeirinhas" e/ou apelidos pejorativos. A homofobia no espaço escolar denominada bullying homofóbico engloba uma "pedagogia do insulto" disseminada por meio de brincadeiras, jogos, piadas, apelidos pejorativos, humilhações, ameaças, mecanismos que têm o poder de silenciamento, dominação simbólica, normalização, marginalização e exclusão da diversidade sexual no espaço escolar, (LOURO, 1997; PRADO; JUNQUEIRA, 2011), ocasionando diversas consequências na vida dos/as jovens LGBT.

Cabe analisar as contradições e reflexões presentes na fala do estudante Júlio: "Seria bom que pelo menos por um dia, os homofóbicos fossem homossexuais, só assim saberiam o preço do preconceito nos 'couros '”. Visto que, ao advertir sobre as consequências dos préjulgamentos e atitudes negativas contra os indivíduos e/ou grupos LGBT, também parece justificar uma certa "moeda de troca" com relação ao preconceito ou ainda uma noção de "castigo" ao assumir a identidade homossexual, por outro lado podemos entender esse comentário como um desabafo que serve de alerta acerca da necessidade de empatia com as identidades/diferenças, pois "ao colocar-se no lugar/na pele do outro", as práticas homofóbicas poderiam ser desestabilizadas e desconstruídas. Dessa maneira, o exercício de desconstrução de preconceitos e discriminações vai sendo disseminado na escola por meio de problematizações e aprendizados das ações de extensão, que possibilitam a discussão das temáticas da Educação Sexual numa abordagem sociocultural e política. 
Outro aspecto que vale destacar foi, após a análise do vídeo com cenas da/o personagem Ivana/Ivan, a emoção de alguns/mas alunos/as, visto, que nesta escola, existe um aluno transgênero e o mesmo estava presente em alguns encontros do projeto. Na fala de Pedro "Será que é realmente necessário, uma pessoa passar por todo esse sofrimento para ser aceita? Poxa o corpo é dela, é uma decisão dela, não é minha, não é sua, o que cabe a mim e a todos/as nós é respeitar", vislumbramos a ideia de aceitação e respeito acerca da transexualidade, entretanto parece se referir às mudanças no corpo de uma pessoa trans como uma simples decisão, quando se trata de uma identidade de gênero construída de modo subjetivo e socioculturalmente.

As identidades de gênero abrangem múltiplas vivências e expressões de masculinidades e feminilidades, englobam os cisgêneros (indivíduos que nascem com sexo biológico compatível com o gênero) e os transgêneros/travestis e transexuais (sexo biológico incompatível com o gênero). Tais identidades, construídas a partir de corpos sexuados e generificados, são instáveis e, portanto, não compreendê-las como algo dinâmico e contingente significa uma forma de marginalizar pessoas que excedem os limites do binarismo masculino/feminino, ao buscarem reinventar seus corpos e desconstruir essencialismos (GOELLNER, 2013; LOURO, 1997; SOUZA, 2018).

Sobre a temática de corpo e sexualidade infantil, notamos algumas visões incoerentes acerca da Educação Sexual, a exemplo da fala de Mário: “criança não tem que saber o que é corpo, se não vão crescer tudo 'pervertidas"', por outro lado Angélica alerta sobre a importância da informação: "as crianças de hoje estão se tornando adultas mais cedo e começando a namorar cedo também, sem informação correta por isso estão sendo pais e mães cedo e pegando IST".

Furlani (2011) explana que, destoante da concepção de muitas pessoas, a Educação Sexual infantil não incentivaria a vivência "precoce" de uma sexualidade. Justamente porque informar, conversar e discutir com as crianças sobre sexualidade, corpo e gênero, significa educá-las para reconhecer seu desenvolvimento desde a infância, adolescência até a vida adulta, favorecendo além da responsabilidade, prevenção e segurança, a dimensão do prazer a partir de uma "cultura de atitudes em face da vida sexual futura" (FURLANI, 2011, p.127).

Jane Felipe (2013, p. 65) ressalta que: "As representações sobre sexualidade, corpo e gênero veiculadas em especial pela mídia têm subjetivação não só adultos, homens e mulheres, mas também têm trabalhado minuciosamente para formação das identidades infantis e juvenis nos nossos dias. [...]" (FELIPE, 2013, p.65). Ademais, a autora adverte que tais reflexões não deveriam provocar um "pânico moral" e/ou "saudosismo de uma infância ingênua", mas impulsionar o questionamento de discursos que produzem diversas Cidadania em Ação: Revista de Extensão e Cultura, Florianópolis (SC), v. 4, n. 1, jan./jun. 2020. 
contradições, inclusive a erotização de corpos infantis em espaços sociais e midiáticos. Nesse raciocínio, Furlani (2011, p. 92) argumenta que:

Hoje, há pelo menos duas justificativas que podem ser usadas para inclusão curricular de uma Educação Sexual infantil que reconhece a importância do aprendizado sobre os cuidados com o corpo, o entendimento das regras sociais sobre nudez e o entendimento do conceito de privacidade. A primeira justificativa é o reconhecimento do autoerotismo (masturbação) como um ato positivo, que deve ser educável; e a segunda justificativa, é o temor do abuso sexual infantil - o que acentua o investimento, no aprendizado da criança, pela autonomia sobre seu corpo.

Além dos vídeos, também trabalhamos com a problematização de músicas que, de modo sutil ou manifesto, continham letras de cunho sexista, machista, misógina e/ou homofóbica, visando estimular um exercício de desconstrução desses preconceitos em torno das questões de sexualidade, corpo e gênero. Com base em Derrida, Louro (2016, p. 43) explica que "[... desconstruir um discurso implicaria minar, escavar, perturbar e subverter os termos que afirma e sobre os quais o próprio discurso se afirma." Nesse caminho, a desconstrução constitui um processo que permite dar visibilidade a contradições e ambiguidades para questionar e desestabilizar discursos fundamentalistas e/ou essencialistas envolvidos na negação da ideia de construção sociocultural das identidades e diferenças (FURLANI, 2011; SILVA, 2000). A saber, destacamos as seguintes músicas e comentários dos/as discentes na tabela 2 :

Tabela 2: Músicas analisadas.

\begin{tabular}{|c|c|c|c|}
\hline Cantor/música & Trecho da música & Aluno/a & Comentário \\
\hline $\begin{array}{l}\text { DJ maluco: forró } \\
\text { do boiola } \\
(23 / 09 / 2019)\end{array}$ & $\begin{array}{l}\text { "Papai dizia esse filho vai ser o orgulho da } \\
\text { família quando ele crescer, não imaginava que } \\
\text { situação o menino já brincava de virar a mão. } \\
\text { Meu deus do céu o que vou fazer esse menino } \\
\text { ver uma cobra já quer se esconder, entrou para } \\
\text { a gangue do machado só para abalar se ver um } \\
\text { pau em pé já quer derrubar. Papaizinho não foi } \\
\text { fácil não raspar as minhas pernas e fazer } \\
\text { pouse no portão, daí veio a fama só para a } \\
\text { balar: tu é gay }\end{array}$ & Carla & $\begin{array}{l}\text { "É uma violência } \\
\text { psicológica, será que } \\
\text { uma pessoa para ser o } \\
\text { orgulho da família } \\
\text { precisa ser } \\
\text { heterossexual?" }\end{array}$ \\
\hline $\begin{array}{l}\text { Forró do sapatão } \\
(23 / 09 / 2019)\end{array}$ & $\begin{array}{l}\text { É sapatão! É sapatão! É sapatão! É sapatão! } \\
\text { Que decepção... A sapatão continua atacando } \\
\text { já estou me preocupando. Ai meu Deus! } \\
\text { Como é que eu vou ficar? Ela tá assanhada. Tá } \\
\text { agarrando a mulherada. Já não tá sobrando } \\
\text { nada pra me namorar. Vejam só, até a minha } \\
\text { namorada. Já chegou pra mim falando, tá } \\
\text { pensando em me deixar. Tudo porque ela quer } \\
\text { mais atenção. E eu trabalho o dia inteiro, } \\
\text { então sai com a sapatão. Vai pra lá! Vai pra lá! } \\
\text { Vai pra lá com esse teu pezão. }\end{array}$ & Beatriz & $\begin{array}{l}\text { "São músicas dançantes, } \\
\text { de melodia envolvente, a } \\
\text { pessoa não observa a } \\
\text { homofobia que existe } \\
\text { nela. É um absurdo esses } \\
\text { termos boiola e sapatão." }\end{array}$ \\
\hline $\begin{array}{l}\text { Enzo rabelo: } \\
\text { perfeitinha } \\
(23 / 09 / 2019)\end{array}$ & $\begin{array}{l}\text { Ela é toda, toda, toda perfeitinha. E o melhor é } \\
\text { que ela é toda, toda minha. Ela é toda, toda, } \\
\text { toda perfeitinha. Dá vontade de guardar numa } \\
\text { caixinha. Pra ninguém roubar }\end{array}$ & João & $\begin{array}{l}\text { "Caraca! Eu enviei essa } \\
\text { música para minha } \\
\text { namorada, achei ela } \\
\text { romântica, ela adorou, se } \\
\text { ela fosse analisar eu } \\
\text { estava ferrado!" }\end{array}$ \\
\hline Pablo do arrocha: & Estou indo embora. A mala já está lá fora & Abel & "Homem não tem que \\
\hline
\end{tabular}

Cidadania em Ação: Revista de Extensão e Cultura, Florianópolis (SC), v. 4, n. 1, jan./jun. 2020. 


\begin{tabular}{|c|c|c|c|}
\hline $\begin{array}{l}\text { por que homem } \\
\text { não chora } \\
(23 / 09 / 2019) \\
(11 / 10 / 2019)\end{array}$ & $\begin{array}{l}\text { Vou te deixar, vou te deixar. Por favor não } \\
\text { implora. Porque homem não chora. } \\
\text { E não pede perdão, e não pede perdão }\end{array}$ & Luísa & $\begin{array}{l}\text { ficar chorando não, } \\
\text { somos fortes, macho não } \\
\text { faz isso, aí é coisa de } \\
\text { mulher que é frágil." } \\
\text { "O machismo está } \\
\text { matando os homens!", }\end{array}$ \\
\hline $\begin{array}{l}\text { Henrique e Diego } \\
\text { (part. Matheus e } \\
\text { Kauan): } \\
\text { Ciumento Eu } \\
(23 / 09 / 2019)\end{array}$ & $\begin{array}{l}\text { Tem uma câmera no canto do seu quarto. Um } \\
\text { gravador de som dentro do carro. E não me } \\
\text { leve a mal. Se eu destravar seu celular com } \\
\text { sua digital. Eu não sei dividir o doce. } \\
\text { Ninguém entende o meu descontrole. Eu sou } \\
\text { assim não é de hoje. É tudo por amor. E tá pra } \\
\text { nascer. Alguém mais cuidadoso e apaixonado } \\
\text { do que eu. Ciumento, eu? E o que é que eu } \\
\text { vou fazer. Se eu não cuidar, quem vai cuidar } \\
\text { do que é meu? Ciumento, eu? }\end{array}$ & Lara & $\begin{array}{l}\text { "Nossa, esse cara é } \\
\text { doente, precisa de um } \\
\text { tratamento psicológico } \\
\text { urgente, temos que fugir } \\
\text { de caras assim! Isso } \\
\text { acaba em violência e até } \\
\text { morte da mulher e o cara } \\
\text { justificando dizendo que } \\
\text { é amor, isso não é amor é } \\
\text { doença, tô fora de } \\
\text { relacionamento assim!" }\end{array}$ \\
\hline $\begin{array}{l}\text { Henrique e } \\
\text { Juliano "Vidinha } \\
\text { de balada" } \\
(08 / 10 / 2019)\end{array}$ & $\begin{array}{l}\text { Tô afim de você e se não tiver 'cê vai ter que } \\
\text { ficar. Eu vim acabar com essa sua vidinha de } \\
\text { balada. E dar outro gosto pra essa sua boca de } \\
\text { ressaca. Vai namorar comigo sim. Vai por } \\
\text { mim igual nós dois não tem. Se reclamar 'cê } \\
\text { vai casar também, com comunhão de bens. } \\
\text { Seu coração é meu e o meu é seu também. }\end{array}$ & Samira & $\begin{array}{l}\text { "E eu que achava essa } \\
\text { música romântica, o cara } \\
\text { é louco, isso não é amor } \\
\text { é posse, vou prestar mais } \\
\text { atenção nas músicas que } \\
\text { escuto." }\end{array}$ \\
\hline $\begin{array}{l}\text { Matheus Yurley } \\
\text { "Zé Droguinha" } \\
(11 / 10 / 2019)\end{array}$ & $\begin{array}{l}\text { Tô curtindo essa novinha. 'Tô querendo essa } \\
\text { novinha } \\
\text { E pra eu não perder ela. Eu vou virar um Zé } \\
\text { Droguinha } \\
\text { Eu dava valor só que ela não dá valor. Preferiu } \\
\text { o Zé Droguinha, não curte trabalhador. }\end{array}$ & Odete & $\begin{array}{l}\text { "Eu me sinto ofendida } \\
\text { com essas músicas, sou } \\
\text { obrigada a escutar nos } \\
\text { corredores da escola, } \\
\text { dentro da sala de aula e } \\
\text { em casa por causa dos } \\
\text { meus vizinhos..." }\end{array}$ \\
\hline $\begin{array}{l}\text { MC GW e MC } \\
\text { MR Bim "Eu Que } \\
\text { Sabotei o Copo } \\
\text { dessa Piranha". } \\
(23 / 09 / 2019)\end{array}$ & $\begin{array}{l}\text { Eu que sabotei o copo dessa piranha. Botei } \\
\text { uma bala boa, uma bala que bate a onda. } \\
\text { Vamo, novinha, quicando de quatro. Ela cai } \\
\text { com a buceta na minha direção. Vamo, } \\
\text { novinha quicando de quatro. Ela cai com a } \\
\text { buceta na minha direção. Potok, potok-pok, } \\
\text { potok no bucetão. }\end{array}$ & Mariana & $\begin{array}{l}\text { "É um desrespeito às } \\
\text { mulheres e estão } \\
\text { estimulando o abuso } \\
\text { sexual, consumo de } \\
\text { drogas e de bebidas } \\
\text { alcoólicas, ensinando } \\
\text { como fazer para violentar } \\
\text { uma mulher." }\end{array}$ \\
\hline
\end{tabular}

Fonte: Dados da pesquisa (2019).

Diante desses comentários acerca das letras musicais, cabe destacar que alguns/mas discentes evidenciaram inquietações e uma análise crítica, entretanto discursos machistas ainda parecem predominar no contexto regional e atravessa o universo escolar, como foi reproduzido na fala do estudante Abel: "Homem não tem que ficar chorando não, somos fortes, macho não faz isso, aí é coisa de mulher que é frágil."

O machismo engloba todo sentimento e/ou comportamento que pressupõe a ideia de que o homem seria superior a mulher, apresenta-se como algo enraizado na sociedade, pois desde antigas civilizações vem afetando negativamente muitos indivíduos e/ou grupos sociais. Essa cultura machista que se propaga ao longo dos tempos tenta manter suas características 
abusivas e repulsivas e, afeta homens e mulheres em todas as esferas sociais (CASTAÑEDA, 2006). A autora acrescenta:

O machismo pode ser definido como um conjunto de crenças, atitudes e condutas que repousam sobre duas ideias básicas: por um lado, a polarização dos gêneros, isto é uma contraposição do masculino e do feminino segundo a qual são não apenas diferentes, mas mutuamente excludentes; por outro, a superioridade do masculino nas áreas que os homens consideram importantes. Assim, o machismo engloba uma série de definições sobre o que significa ser homem e ser mulher, bem como toda uma forma de vida baseada nele (CASTANEDA, 2006, p.16).

Nesse contexto, cabe ressaltar a fala da estudante Luísa: "O machismo está matando os homens", pois corrobora com o entendimento do machismo como algo tóxico e prejudicial também para os homens, pois estes são limitados a uma masculinidade hegemônica e tóxica, ou seja, reproduzem uma imposição sociocultural marcada pela dominação do masculino sobre o feminino, reforçando práticas tóxicas, como violências psicológicas e físicas contra mulheres e, assim, corrobora com relações de gênero desiguais (CONNELL; MESSERSCHMIDT, 2013).

No feminismo pós-estruturalista, o conceito de gênero problematiza processos socioculturais e linguísticos que (re)produzem diferenças e desigualdades nas relações entre homens e mulheres, nomeando seus corpos como sexuados e generificados. Os movimentos feministas defendem a equidade entre os gêneros, reconhecendo a multiplicidade e liberdade de sujeitos, saberes e práticas, ao instigar posicionamentos críticos e políticos em um contexto social heterogêneo e marcado pelo gênero (HARAWAY, 1995; NICHOLSON, 2000; MEYER, 2004; SCOTT, 2012). Assim, é importante lembrar que os homens também precisam do feminismo para alcançar essa equidade social, encorajando expressões e vivências plurais de masculinidades e feminilidades e a desconstrução de assimetrias nas relações de gênero.

A partir da problematização de letras musicais que reproduzem a homofobia, as seguintes falas das estudantes Beatriz e Carla merecem destaque: "São músicas dançantes, de melodia envolvente, a pessoa não observa a homofobia que existe nela. É um absurdo esses termos 'boiola' e 'sapatão'”; “É uma violência psicológica, será que uma pessoa para ser o orgulho da família precisa ser heterossexual?’. Nesse olhar, enfatiza-se que a gravidade da homofobia não consiste somente nas práticas de violência física, mas, também nas manifestações de violência psicológica, presente nas ofensas, na linguagem cotidiana e nas representações caricaturais que ridicularizam indivíduos e grupos LGBT (BORRILLO, 2009).

$\mathrm{Na}$ maioria das escolas, os insultos mais frequentes nos corredores ou na própria sala de aula são apelidos pejorativos, como "bicha", "boiola", "viado". Trata-se de uma forma de intimidar e subestimar os colegas, utilizando um tipo de humilhação que afeta a definição da 
identidade masculina. Para se referir a lésbicas e/ou meninas que diferem do padrão de feminilidade costumam ser empregados termos como "moleque", "sapatão". Esses insultos contra LGBT ou afins reafirmam marginalizações em decorrência do não enquadramento na heteronormatividade. Nessa lógica, homens e mulheres deveriam se comportar conforme rótulos e diretrizes que definem, socioculturalmente, uma forma hegemônica de masculinidade e de feminilidade. Portanto, a mensagem implícita é: quando alguém rompe as normas recebe uma punição, insultos, exclusões e todos os tipos de humilhações toleradas por nosso ambiente social imediato, como a família, a escola, o bairro, o trabalho, entre outras instâncias sociais (PLATERO, 2008).

A partir dessa análise, evidenciamos que artefatos culturais, como vídeos e músicas, por vezes, reproduzem discursos essencialistas e preconceituosos acerca das dimensões de sexualidade, corpo e gênero. No entanto, por meio de um exercício de problematização dessa linguagem machista, sexista e homofóbica, os artefatos culturais também constituem instrumentos potentes para a desconstrução de preconceitos e discriminações.

\section{CONCLUSÕES PROVISÓRIAS}

As ações desenvolvidas no projeto de extensão acerca da Educação Sexual possibilitaram aos/as estudantes e demais participantes, aprendizados e vivências imprescindíveis para a formação pessoal, social e profissional, assim como (in)formações sobre questões de sexualidade, corpo e gênero, para além de uma abordagem focada na saúde sexual e reprodutiva. Os depoimentos dos/as alunos/as, evidenciaram que a desconstrução de preconceitos e discriminações será possível por meio da multiplicação de ações de extensão, pesquisa e ensino que incorporem essas temáticas da Educação Sexual numa perspectiva sociocultural e política. Apesar disso, observamos que, no contexto regional cearense, (in)formações acerca da Educação Sexual ainda são mantidas distantes dos/as alunos/as tanto pela família quanto pela escola. Visto que, fomos educados/as em uma cultura machista, misógina, sexista e homofóbica, logo essa desconstrução exige tempo, dinamismo e ações plurais e políticas.

Enfatizamos que a Educação Sexual constitui um processo contínuo e sistemático fundamental para a formação docente e discente, pois abrange saberes e práticas que ultrapassam a dimensão conteudista e biologicista dos currículos escolares e acadêmicos. Sobretudo, ao evidenciar o quanto "a vida" deve estar imersa em todo o processo de ensino e aprendizagem, afinal “[...] se não houver vida naquilo que aprendemos, então não há educação, formação e muitos menos aprendizagem" (MOSÉ, 2013, p.82). Portanto, ressaltamos a relevância da Educação Sexual incorporada nos currículos acadêmicos e 
escolares de forma permanente, por meio de variadas estratégias didático-metodológicas, como a problematização de artefatos cultuais, que favoreçam o engajamento de estudantes, docentes e toda a comunidade escolar, criando possibilidades para a desconstrução de preconceitos acerca das dimensões de corpo, gênero e sexualidade. 


\section{REFERÊNCIAS}

BENEVIDES, B. G.; NOGUEIRA, S. N. B. (Org.). Dossiê dos assassinatos e da violência contra travestis e transexuais brasileiras em 2019. São Paulo: Expressão Popular, ANTRA, IBTE, 2020.

BORRILLO, D. A homofobia. In: LIONÇO, T.; DINIZ, D. (Org.). Homofobia \& educação: um desafio ao silêncio. Brasília: Letras Livres, 2009.

BUTLER, J. Corpos que pesam: sobre os limites discursivos do sexo. In: LOURO, G. L. (Org.). O corpo educado: pedagogias da sexualidade. 2. ed. Belo Horizonte: Autêntica, 2000. p.151-174.

CASTAÑEDA, M. Machismo Invisível. Tradução de Lara Christina de Malimpensa. São Paulo: A Girafa Editora. 2006.

CONNELL, R. W.; MESSERSCHMIDT, J. W. Masculinidade hegemônica: repensando o conceito. Estudos Feministas, Florianópolis, v. 21, n. 1, p.241-282, jan. abr./2013.

DORNELLES, P.G. A (hetero)normalização dos corpos em práticas pedagógicas na Educação Física escolar. Tese (Doutorado). Faculdade de Educação, Universidade Federal do Rio Grande do Sul, Porto Alegre, 2013.

FELIPE, J. Erotização dos corpos infantis. In: LOURO, G. L.; FELIPE, J.; GOELLNER, S. V. (Org.). Corpo, gênero e sexualidade: um debate contemporâneo na educação. 9. ed. Petrópolis: Vozes, 2013. p.54-66.

FREITAS, A. P et al. Intervenção com adolescentes por meio de grupos focais: uma estratégia de democratização escolar. Conexão UEPG, v. 12, n. 3, p. 546-557. 2016.

FOUCAULT, M. História da Sexualidade 1: a vontade do saber. 2. ed. São Paulo: Paz e Terra, 2015.

Ética, Sexualidade e Política. Organização de Manoel Barros da Motta. 3. ed. Rio de Janeiro: Forense Universitária, 2017. (Coleção Ditos \& Escritos V).

FURLANI, J. Educação Sexual — quando a articulação de múltiplos discursos possibilita sua inclusão curricular. Perspectiva, Florianópolis, v. 26, n. 1, p. 283-317, jan./jun. 2008.

Educação sexual na sala de aula: relações de gênero, orientação sexual e igualdade étnico-racial numa proposta de respeito às diferenças. Belo Horizonte: Autêntica, 2011.

GOELLNER, S. V. A produção cultural do corpo. In: LOURO, G. L.; FELIPE, J.;

GOELLNER, S. V. (Org.). Corpo, gênero e sexualidade: um debate contemporâneo na educação. 9. ed. Petrópolis: Vozes, 2013. p. 30-42.

GOMES, A. A. Apontamentos sobre a pesquisa em educação: usos e possibilidades do grupo focal. EccoS - Revista Científica, São Paulo, v. 7, n. 2, p. 275-290, jul./dez. 2005.

HARAWAY, D. Saberes localizados: a questão da ciência para o feminismo e o privilégio da perspectiva parcial. Cadernos Pagu, Campinas, v. 5, p. 7-41, 1995. 
JUNQUEIRA, R. D. Políticas de educação para a diversidade sexual: escola como lugar de direitos. In: LIONÇO, T.; DINIZ, D. (Orgs.). Homofobia \& Educação: Um desafio ao silêncio (pp.161-193). Brasília: LetrasLivres: EdUnB, 2009, p.161-193.

LEIS, H. R. A sociedade dos vivos. Sociologias, v. 5, n. 9, p. 340-353, jan./jun., 2003.

LOURO, G. L. Gênero, sexualidade e educação: uma perspectiva pós-estruturalista. Petrópolis: Vozes, 1997. jul./dez. 2000. Corpo, escola e identidade. Educação \& Realidade, Porto Alegre, v. 25(2):59-76, Teoria queer: uma política pós-identitária para a educação. Estudos Feministas, Florianópolis, v. 9, n. 2, p. 541-553, 2001.

Heteronormatividade e Homofobia. In: JUNQUEIRA, R. D. (Org.). Diversidade Sexual na Educação: Problematizações sobre a homofobia nas escolas. Brasília: Ministério da Educação, Secretaria de Educação Continuada, Alfabetização e Diversidade, UNESCO. 2009, p.85-94.

Um corpo estranho: ensaios sobre sexualidade e teoria queer. 2 ed. Belo Horizonte: Autêntica, 2016.

MAGALHÃES, J. C; RIBEIRO, P. R. C. Artefatos culturais: algumas possibilidades para promoção de uma educação para sexualidade. Diversidade e Educação, v.1, n.1, p. 45-46, jan./jun., 2013.

MEYER, D. E. E. Teorias e políticas de gênero: fragmentos de histórias e desafios atuais. Revista Brasileira de Enfermagem, Brasília, v. 57, n. 1, p. 13 -18, jan./fev. 2004.

MOSÉ, V. A escola e os desafios contemporâneos. Rio de Janeiro: Civilização Brasileira, 2013.

NICHOLSON, L. Interpretando o gênero. Estudos Feministas, Florianópolis, v. 8, n. 2, 2000 .

PLATERO, R. La homofobia como elemento clave del acoso escolar homofóbico. Algunas voces desde Rivas Vaciamadrid. Información Psicológica, v.94, 71-83, 2008.

PRADO, M. A. M.; JUNQUEIRA, R. D. Homofobia, hierarquização e humilhação social. In: VENTURI, G.; BOKANY, V. (Orgs.) Diversidade sexual e homofobia no Brasil. São Paulo: Editora Fundação Perseu Abramo, 2011, p.51-71.

SCOTT, J. Os usos e abusos do gênero. Projeto História, São Paulo, n. 45, p. 327-351, dez. 2012.

SILVA, E. P. Q. Corpo e sexualidade: experiências em salas de aula de ciências. Periódicus, Salvador, v. 1, p. 138-152, 2014.

SILVA, T. T. Teoria Cultural e Educação: um vocabulário crítico. Belo Horizonte: Autêntica, 2000. 
Documentos de identidade: uma introdução às teorias do currículo. 3. ed. Belo Horizonte: Autêntica, 2015.

SOARES, R. Pedagogias Culturais produzindo identidades. In: BRASIL (TV Escola/Salto para o futuro). Educação para igualdade de gênero, Ano XVIII, Boletim 26, p. 47-53, nov. 2008.

SOUZA, E. J. Educação sexual "além do biológico": problematização dos discursos acerca de sexualidade e gênero no currículo de licenciatura em biologia. Tese (Doutorado em Educação). Programa de Pós-Graduação em Educação, Faculdade de Educação, Universidade Federal do Rio Grande do Sul, Porto Alegre, 2018.

SOUZA, E. J.; SILVA, J. P.; SANTOS, C. Diversidade sexual e homofobia na escola: (des)conhecimento e vivências de docentes. Educação em Questão, Natal, v. 54, n. 41, p. 111-138, maio/ago. 2016. 